\title{
Sacrificios y «mala muerte» en el Registro Arqueológico de los Yacimientos Ibéricos
}

\author{
Sacrifices and «violent death» in the \\ Archeologial Registry in the Iberican \\ Archeological Sites
}

\begin{abstract}
Arturo Oliver Foix*
RESUMEN ABSTRACT

La presencia cada vez más abundante en el registro arqueológico ibérico de restos humanos fuera de las necrópolis, nos lleva a plantear una serie de hipótesis para dar explicación a estos hallazgos.

The presence, each time more plentiful, in the Iberian archaeologist registers of human remainder out of the cemetery, invite us to think about one series of hypothesis for explain this discoveries.
\end{abstract}

\section{PALABRAS CLAVE}

Ibérico, restos humanos, sacrificios, ritos.
KEY WORDS

Iberian period, human remainder, sacrifice, ritual

\section{INTRODUCCIÓN}

La Cultura Ibérica como bien se sabe, tiene en el rito funerario basado en la cremación del cadáver uno de sus principales rasgos diferenciales, el cual es continuidad del tratamiento que recibía el cuerpo humano tras la muerte ya en épocas anteriores a la iberización, pues en el Bronce Final, en todo lo que posteriormente será la región ibérica, se establecerá la purificación de la persona a través del fuego. No obstante, tanto como se va avanzando en el conocimiento del mundo ibérico y superado el periodo de investigación en el que la pura clasificación de materiales y su datación era el objetivo primordial, y tras adentrarse en cuestiones

* Museo de Bellas Artes de Castellón. 
más inmateriales como es el caso del estudio de la composición de la sociedad o de la propia religión, a través del registro arqueológico se va obteniendo una serie de información que permite conocer con mayor precisión los diferentes ritos. Así, hoy por hoy, nadie duda que las clásicas necrópolis ibéricas no representan el cien por cien de los individuos muertos en las poblaciones ibéricas, aunque seguimos sin conocer cual es el rito de enterramiento que empleaban los estamentos sociales situados en la parte baja de la pirámide social.

El arqueólogo, al aplicar nuevas metodologías y considerar todo tipo de posibilidades y materiales en la investigación, en los últimos años ha ido aumentando el número de datos que permiten empezar a generalizar elementos rituales que inicialmente eran hechos únicos, como es el caso de los restos humanos inhumados, por ejemplo, las llamadas inhumaciones infantiles, que en su día merecieron una monografía (Gusi, F., 1989), lo mismo sucede con los restos humanos no sepultados localizados en zonas de hábitat, sobre los que llamamos ya la atención hace unos años (Oliver, A., 1995), o los que se localizan en lugares de almacenaje, como son los silos.

La heterogeneidad de enterramientos y la localización de restos humanos fuera de las necrópolis va en aumento, lo que poco a poco descarta la simplicidad y unicidad de los ritos funerarios, identificándose una serie de variantes algunas de las cuales están relacionadas a su vez con la diversidad de creencias, con la complejidad de la composición de la sociedad, con las diferentes tradiciones regionales, etc., todo ello indica la complejidad y diversidad de la Cultura Ibérica dentro de esa homogenización que existe en todo el sur y el levante peninsular, así como en el mediodía francés.

Presentamos pues, en este trabajo que ofrecemos en homenaje a la profesora Victoria Cabrera, una aproximación a esta problemática religiosa y social de la Cultura Ibérica. Un periodo histórico muy alejado al que ella dedicó sus esfuerzos como investigadora, unido tan solo, al igual que con el resto de la Historia, por un final único, como el que nos ha separado de la docente, de la arqueóloga y de la que siempre será recordada Dra. Cabrera Valdés.

\section{INHUMACIONES EN LUGARES DE HÁBITAT}

Las llamadas inhumaciones infantiles ibéricas se encuentran perfectamente tipificadas y descritas en gran número de publicaciones, ya sean referidas a un yacimiento en concreto o a estudios de conjunto; como compendio continúa siendo válido el número monográfico editado por el SIAP de la Diputación de Castellón, al que hemos hecho mención más arriba, o la recopilación que realiza F. Gusi (1992).

Este rito que se localiza desde el Languedoc a Murcia, se ha relacionado siempre con la Cultura Ibérica, pero sus orígenes parecen encontrarse en los últi- 
mos periodos de la Edad del Bronce, como vemos en los yacimientos de la $\mathrm{Pe}$ drera de Vallfogona, en Carretelà de Aitana, en el Tossal de les Tenalles de Sidamon, els Vilars de Arbeca, Moleta del Remei de Alcanar, Peña de la Dueña de Teresa o los Azafranales de Fraga, todo ello en la parte occidental de lo que será posteriormente la región ocupada por los iberos. Pero además, este rito continúa todavía en los siglos I y II, una vez desaparecida la Cultura Ibérica. En plena época romana, se pueden citar los enterramientos infantiles del Antiguo Portal de la Magdalena de Lérida, en el Tossal del Moro de Corbins, en Denia, o en Celsa de Velilla de Ebro. El rito de inhumación también se encuentra presumiblemente en la península Itálica (Pérez, A., 1998). Un rito que puede existir pues, en el Mediterráneo occidental difundido entre las culturas ribereñas, y en el cual no hay que buscar influencias concretas, como es el caso de la fenicio-púnica, o la propiamente romana para los momentos tardíos, ya que posiblemente, al igual que ocurre en otros aspectos religiosos, sociales y culturales, estamos ante un sustrato común de las diferentes culturas asentadas en una amplia región mediterránea.

Dentro de las inhumaciones en edificios, hay que detallar el hallazgo de los restos de un joven sobre una losa, y que según su excavador $D$. Fletcher, el enterramiento pertenece sin ninguna duda al momento de la construcción de un edificio, el cual podría tener una funcionalidad cultual, en el Cabezo del Tío Pío de Archena. La pared $\mathrm{G}$ de la construcción se asienta sobre la losa y sobre el propio cráneo del cadáver (Fletcher, D., 1947). La singularidad del hallazgo y los pocos datos que tenemos nos hacen ser precavidos sobre su interpretación. No obstante, hay que indicar que esta inhumación en cuanto a situación, tiene las mismas características que las infantiles.

Una perduración de este tipo de rito en época romana podrían ser los esqueletos de la muralla de Bilbilis (Martín, M., 1975; 1982), sean o no sacrificios, lo cierto es que estamos ante la presencia de un rito en donde se emplean restos humanos además de animales, combinación que vemos en época ibérica, por ejemplo en el Puig de la Nau. La protección de los muros de la ciudad, al igual que sucede así mismo en el Puig de la Nau con el deposito del recién nacido en la muralla de este asentamiento ibérico, podría ser la finalidad del rito.

El rito de enterramiento de niños se ha querido explicar por el reconocimiento o no, de los niños entre la sociedad, y por tanto, como un rito funerario relacionado con la edad del finado, tal como podría indicar Plinio al decir que es costumbre universal no quemar a ningún niño antes de la erupción de los dientes (N.H. VII, 16). La diferencia de enterramiento que han tenido los niños recién nacidos a lo largo de la Historia europea, prácticamente hasta la actualidad, ha contribuido a esta relación. No obstante, podemos plantear varios aspectos que nos llevan a hipotizar sobre la probabilidad de un rito propiciatorio y de protección, que en algunos casos puede tener como efecto el sacrificio del recién nacido, tal y como ya se ha planteado en algunas ocasiones, prácticamente desde la identificación del rito (Barrial, O., 1990). 
Los enterramientos infantiles de niños menores de un año se encuentran también en necrópolis, ya sea cremados o inhumados, al menos es lo que se ha identificado en las cementerios del sudeste. En los Villares de Hoya Gonzalo (Reverte, J.M., 1990) los menores de un año son cremados. En la necrópolis del Cigarralero de Mula se encuentran también enterramientos infantiles, ocupando un lugar secundario en el espacio funerario, asociándose a estructuras tumulares, pero sin ser cubiertas por ellas. Pero en esta ocasión los enterramientos infantiles pueden ser de cremación o de inhumación, considerándose que los enterramientos de inhumación corresponden a niños menores de un año (Santonja, M., 1992; 1993).

Aunque parte de los enterramientos se dan en vivienda, hay que indicar que en algunas ocasiones se encuentran en almacenes, como vemos en el Puig de la Nau de Benicarló, situación que se repite incluso en la etapa romana, como sucede en Denia o en Lérida (Pérez, A., 1998). En el mismo yacimiento del Puig de la Nau se han localizado restos de huesos infantiles en la propia muralla. En la Moleta del Remei de Alcanar también está en zonas comunales de posible almacenaje de grano. Por tanto, no se encuentran tan solo en espacios domésticos, y no se pueden vincular a ritos de carácter familiar o meramente funerarios.

Estos enterramientos infantiles, además, presentan las mismas características que los llamados depósitos fundacionales de animales, o viceversa. Debajo de los pavimentos de las edificaciones, junto a los muros, animales jóvenes.

En muchas ocasiones estamos ante un enterramiento secundario, incluso tan solo hay una parte del esqueleto que se ha enterrado una vez descarnado.

Todo ello nos lleva a plantear que estamos ante un sacrificio perteneciente a un rito propiciatorio o de protección, ya sea para la familia que habita la vivienda, para los productos que guarda el almacén o la muralla que defiende el pueblo. Un sacrificio que en la mayoría de las ocasiones es sustitutorio. Así, mientras que los enterramientos infantiles localizados en posición fetal, es decir enterramientos primarios, podrían corresponder al sacrificio, en otras ocasiones el niño ha sido sustituido por los huesos de otro recién nacido que ya estaba muerto, de allí que tan solo encontremos parte del esqueleto, o incluso estén mezclados e incompletos varios esqueletos. El que los depósitos de animales presenten las mismas características que los niños, o que restos de animales se encuentren junto a resto de niños, puede señalar la sustitución del niño por un animal.

La dificultad que entraña el conocer la causa de la muerte del recién nacido, hace difícil confirmar la hipótesis de forma clara. Lo mismo sucede con la imposibilidad de conocer el sexo de los recién nacidos, el cual no se puede discernir por la osteología, ni hemos podido averiguarlo por la identificación del cromosoma $Y$, pues los análisis genéticos realizados no han proporcionado la secuencia de ADN. 


\section{ENTERRAMIENTOS MÚLTIPLES}

Dentro del registro arqueológico que nos da pie a plantear hipótesis de posibles muertes no naturales, se encontraría el caso de los enterramientos múltiples de adultos, o adultos y niños, localizados en las necrópolis ibéricas. Sería el caso de la tumba 200 de la necrópolis del Cigarralero de Mula, la sepultura más rica localizada en el yacimiento, y en cuya urna hay mezclados los restos de un hombre y una mujer. Lo mismo sucede con la tumba 204 y la 293. En este último caso, la superposición de los ajuares y de los restos cremados podría indicar una diferencia de tiempo, ya que no están mezclados como en los otros, al menos no se han quemado simultáneamente (Santonja, M., 1993). También las tumbas 42bis/4 y la 48/3 de los Villares de Hoya Gonzalo, presentan de forma mezclada, restos de dos individuos hombre y mujer, entre 30 y 40 años (Reverte, J.M., 1990). En otra necrópolis, en este caso en la provincia de Jaén, la de Hornos de Peal en la localidad de Peal de Becerro, se localiza un enterramiento que aunque separado en dos urnas diferenciadas, una para la mujer y otra para el hombre, se ha podido comprobar que ambos cuerpos fueron quemados a la vez en la misma pira funeraria (Ruiz, A., Molinos, M., 2005).

Lo mismo sucede con la combinación más abundante de niño y mujer. Se descarta la posibilidad de que sea una muerte de ambos en el parto, pues en algunas ocasiones el niño presenta varios meses de vida. Así, en Pozo Moro hay cuatro tumbas de mujer con niños de uno y dos años (Reverte, J.M., 1985). La tumba 118 del Cigarralejo tiene un lactante sin cremar y un posible varón adulto, lo que nos aleja de la muerte por parto. Lactante y mujer se encuentran en la tumba 140, 504, 518, y la 528, en estas dos últimas tumbas el niño es mayor de un año (Santonja, M., 1993). En la necrópolis del Turó dels Dos Pins en Cabrera de Mar en la tumba 34-3 hay un niño una mujer, en la 51(dins 67) un adulto y un niño, y un adulto masculino y niño en la tumba 51 (dins 29), mientras que en la tumba 38-1 se encuentra un neonato y una mujer, lo que podría interpretarse fácilmente en este caso, como una muerte por causa del parto (Campillo, D., 1993). En la necrópolis del Torrelló del Boverot de Almazora la tumba 20 presenta los restos de una mujer adulto y un niño de 5 años (Clausell, G., 1999). En la sepultura tres del Mas Nou de Bernabé de Tirig, hay restos de una mujer y un niño que no supera los dos años. En ella la calidad de las cremaciones, muy similar, induce a pensar que si el depósito no fue simultáneo, no debió mediar mucho tiempo entre ambos, y tuvo lugar en las mismas condiciones de combustible, oxigenación, etc (Oliver, A., 2005). La necrópolis del Cabezo de Lucero en Guardamar del Segura, presenta tumbas con más de un individuo. En la P.26b, se depositaron los restos de una mujer adulta más dos niños, uno entre 0 y 7 años y otro de 8 a 14 años en urnas diferenciadas. En la tumba P.47 se recoge la cremación de un adulto sin conocerse el sexo, un individuo perinatal y otro infante de 0 a 7 años, todo junto. En la tumba $P$. 75 se quemaron sucesivamente dos cuerpos, uno masculino y el otro posiblemente femenino, los cuales fueron enterrados en urnas separadas. Una de las urnas lle- 
va restos de otro cuerpo, tal vez se juntaron al recogerlo en la pira. En la tumba $P$. 91 se enterró un adulto de sexo desconocido, junto a un infante de unos dos años, todo mezclado. En esta necrópolis en la tumba P. 93 y P. 94 hay un niño en cada uno de ellas con una edad entre 0 y 7 años (Aranegui, C., et al., 1993).

Indudablemente, tal y como indica el profesor J. M. Reverte en el estudio osteológico de Pozo Moro de Chinchilla, se podría estar ante un proceso infeccioso de la pareja enterrada, ya sea dos adultos o un adulto y un infante, pero no podemos dejar de lado la posibilidad de que estemos ante una muerte violenta debido a la muerte natural de uno de los dos fallecidos. El acompañamiento a la vida de los muertos, ya sea por su condición de cónyuge de la persona finada que es de un estamento social elevado, como resulta ser el caso de la tumba 200 del Cigarralejo, o bien porque la muerte de la madre o el hijo requiere la presencia del otro en el más allá para su cuidado, o por ser individuos complementarios, o simplemente por «haber permitido o propiciado» la muerte de uno de ellos, por lo que se estaría prácticamente ante un castigo punitivo, no debe resultar extraño.

\section{ENTERRAMIENTO EN CUEVA}

Bien es conocido que desde Andalucía a Cataluña los Cultura Ibérica tiene en las cuevas un lugar sagrado de culto y de peregrinación, por lo que como ocurre en otras culturas, las entrañas de la Tierra, el inframundo, la creencias ctónicas, a las que se accede a través de las cuevas, ejerce una atracción de carácter espiritual, y más aún si en este interior de la madre tierra está el líquido purificador del agua.

Aunque los restos arqueológicos localizados en las cuevas sagradas ibéricas son ciertamente abundantes, tan solo en una ocasión parece constatarse el uso de la cueva como un lugar de enterramiento, hecho que era corriente durante toda la Prehistoria, hasta la introducción de las sepulturas megalíticas en algunas zonas, o la cremación en otras. Este hecho se registra en la Cova Freda de Collbató en la montaña de Montserrat (Font, 1980). Se trata además de una inhumación y no de una cremación, según indican los restos de tres individuos de características antropológicas alpinas, uno de los cuales estaba cubierto con cerámica ibérica.

El hecho de que sea un tipo de enterramiento completamente diferente a los convencionales de la Cultura Ibérica, tanto por su situación, como por ser una inhumación, nos hace pensar que estamos ante una muerte singularizada, a la que hoy por hoy, no se puede dar explicación, y que en principio no parece que sean muertes violentas.

\section{5. ¿INHUMACIONES EN TÚMULO?}

Otro caso único dentro de los enterramientos no tipificados de la Cultura Ibérica es el localizado en el yacimiento del Coll del Moro de la Serra d'Almos en Tivisa. 
Se trata de un esqueleto semiquemado, perteneciente a una mujer, en posición supino prono, el brazo flexionado bajo el cuerpo y contra el tórax, y cubierta por piedras y tierra formando un pequeño túmulo, y en un lecho de cenizas. Tenía la cabeza fracturada en buena parte de la frente, cara y mentón, y se apoya sobre cuatro o cinco piedras llanas. El yacimiento fue excavado y dado a conocer por $\mathrm{S}$. Vilaseca (1953), resultando difícil interpretarlo a partir de los datos que da el excavador. Ha sido revisado recientemente, otorgándole una datación del siglo VI a.C. (Cela, X., Noguera, J., Rovira, M., 1999).

Dentro de los paralelos de este tipo de enterramiento cabría mencionar un enterramiento de inhumación del que no se tiene una adecuada documentación, se trata de una inhumación de la necrópolis del Molar de San Fulgencio, que cita J. Lafuente (1929), y S. Nordström (1973) vuelve a mencionar, pero como dos inhumaciones, y que L. Abad y F. Sala (1991), consideran que es la que indica J.J. Senent (1930), como una posible tumba familiar cubierta por un túmulo de tierra y piedra. J.J. Senent menciona una inhumación muy profanada, hallada durante su primera campaña de excavación, y otra también muy removida, tal vez familiar, cubierta por un túmulo de tierra y piedras. Pero los datos de esta última tumba los dieron los propietarios del terreno, por lo que el hallazgo no procede de una excavación. Estaríamos pues, ante un enterramiento de inhumación y con un posible túmulo de piedras y tierra, por tanto, paralelizable con la inhumación publicada por S. Vilaseca, pero desconocemos el estado de los huesos, y se sitúa en un contexto diferente.

Estas inhumaciones nos llevan a compararlas con las localizadas en Andalucía, pertenecientes, no obstante, a momentos anteriores. Por ejemplo, la de la necrópolis de la Joya de Huelva (Garrido, J.P., et al., 2000) o de la Cruz del Negro de Carmona (Maier, J., 1992). En el primer caso hay ofrendas funerarias humanas con fractura parietal derecho, que se relacionan con los «lapidados» de la necrópolis de Acebuchal en Carmona excavada por J. Bonsor. Se consideran ofrendas de esclavos o personas marginales muertas con lapidación ritual. Al igual que en el Coll del Moro los cráneos se encuentran fracturados, y están rodeados de piedras, situándose los restos sobre un nivel de cenizas, y en ambos yacimientos presenta una posición anómala para un enterramiento. En la Cruz del Negro la incineración puede ir acompañada de inhumaciones adultas, concretamente mujeres, que presentan el cráneo aplastado. También una inhumación infantil de esta necrópolis poseía el cráneo aplastado. Así pues, en Andalucía los cráneos aplastados en la etapa orientalizante, se dan en las necrópolis de Acebuchal, La Joya y La Cruz del Negro. No podemos dejar de mencionar los enterramientos infantiles gaditanos con cráneo aplastado de Cádiz pero de época romana (Corzo, R., 1989).

Todo ello nos permite hipotizar sobre una posible lapidación en el Coll del Moro de Tivisa, o bien ante la exposición de restos, rito sobre el que después volveremos, o un abandono accidental tras la destrucción del asentamiento, hipótesis que plantea J. Noguera (2002), quien también recoge la propuesta de B. Dedet para los 
individuos semiquemados por morir fuera de la comunidad, o que mueren por motivos no convencionales o naturales, enfermedades concretas, ejecuciones, etc., (Dedet, B., 1992). Indudablemente la falta de datos claros sobre el Coll del Moro permite muchas conjeturas.

Podemos mencionar también dentro de este grupo, el individuo localizado en el yacimiento francés de Cayla de Mailhac, junto a la muralla. El cadáver situado en tierra y con piedras sobre él sin orden, y con una herida en el frontal, características que nos acercan a los restos mencionados en este apartado (Dedet, B., Schwaller, M., 1990).

\section{ENTERRAMIENTOS Y RESTOS HUMANOS EN SILOS}

Los yacimientos conocidos como campos de silos ibéricos, o los silos aislados, se localizan en el noreste peninsular y el mediodía francés, siendo la población de Amposta, junto a la desembocadura del río Ebro, la más meridional que presenta este tipo de almacenaje de grano. Aunque la funcionalidad de los silos tal y como es sabido por todos es el almacenaje, entre el material de la obliteración de estas cavidades como depósitos de cereal, se han localizado restos humanos, los cuales podemos agrupar en dos tipos, los que provienen de los rellenos, siendo partes esqueléticas sin conexión y aisladas, y los que provienen de enterramientos. Los rellenos de los silos se han datado desde finales del siglo III al I a.C.

La primera publicación sobre el tema está referida al hallazgo de una mandíbula humana, dos cráneos y huesos largos procedentes del silo I de Burriac en Cabrera de Mar (Ribas, M., Martín, R., 1960-1961). También en los campos de silos de Cabrera de Mar, y concretamente en el silo 31 de Can Miralles-Modolell, se localizó un cráneo de un individuo adulto femenino (Pujol, J., García, J., 19821983). En la Avinguda dels Ferrocarrils Catalans de Barcelona en un silo había un cráneo de hombre adulto, entre 30 y 40 años (Vives, E., Miró, C., 1991). En Mas Castellar de Pontós, en el silo SJ31, se exhumaron varios huesos humanos pertenecientes a la caja torácica de un individuo adulto entre 35 y 40 años (Agustí, B., 2002). No obstante, sin duda, los más conocidos son los dos cráneos de hombres adultos provenientes del Puig de Sant Andreu de Ullastret, silo 146, situado cerca de una poterna de la muralla, debido a que presentan un clavo de hierro en su hueso frontal sobre la línea sagital (Campillo, D., 1976-1978). También huesos se han localizado en los silos 8, 61, 72 de Ensérune en Nissan lez Ensérune. Son adultos y uno de ellos es mujer. En otros dos silos del asentamiento, una calota craneal y dos cráneos con huesos humanos. En el silo 14, el 5 y el 1-55, del campo de silos del yacimiento, hay fragmentos de calota craneal, un cráneo, dientes, y huesos calcinados (Dedet, D., Schweller, M., 1990).

Los enterramientos propiamente dichos se encuentran en varias ocasiones. En el campo de silos del Bosc del Congost de Sant Julià de Ramis dos de ellos tenían 
restos humanos. En el lado oeste del silo 17, con una orientación norte sur, estaba parte de un enterramiento, tan solo tenía una arracada como ajuar. El cuerpo fue depositado una vez el silo se había rellenado, dentro de una fosa rectangular. Es un individuo adulto del que no se ha podido determinar el sexo. También en el silo 59 , y así mismo en su parte oeste, se localizó otro enterramiento en decúbito supino pero en peor estado de conservación. Al igual que el anterior corresponde a un individuo adulto, y aunque es grácil no se ha podido saber el sexo (Agustí, B., et al., 1998). No presentaba ningún material de acompañamiento (Burch, J., et al., 1995). En la montaña de Montjuic, en el yacimiento de la Avinguda dels Ferrocarrils Catalans, en un silo se localizó un enterramiento de individuo adulto entre 30 y 40 años, mujer, encontrándose en posición fetal (Vives, E., Miró, C., 1991). Un individuo adulto se ha localizado en los silos de Sant Sebastià de la Guarda de Palafrugell (Agustí, B., 1999). Otro enterramiento del que no tenemos datos es el de Quintana de Cervià de Ter (Agusti, B., et al., 1998). En el yacimiento francés de Ensérune, Nissan lez Ensérune, en el silo 5, hay un esqueleto en conexión, de un individuo mayor de 30 años, mujer, se encuentra en la parte norte del silo y está cubierto con piedra y tierra. En el silo 55 hay otro individuo en el centro del silo. Ambos están en decúbito supino. En La Lagaste de Pomas et Rouffiac, se localizó un niño de aproximadamente trece años en un silo, y otro silo contenía restos de una mujer adulta (Dedet, B., Schweller, M., 1990).

\section{RESTOS HUMANOS EN LUGARES DE HÁBITAT}

Entre el registro arqueológico que nos indica la existencia de restos humanos en los poblados ibéricos, podemos realizar dos grupos diferenciados, los que presentan evidencias de que estamos ante un rito social o religioso, y otro grupo formado por restos óseos de diferentes partes del esqueleto, aunque predominan los cráneos y mandíbulas, sin muestra de ningún tipo de rito.

Dentro del primer grupo situamos el cráneo localizado en la Illa d'en Reixach de Ullastret, pertenece al siglo $\mathrm{V}$ a.C., y aunque no se ha conservado el clavo los restos de óxido existentes alrededor del agujero denuncian el enclavamiento. Además según el análisis antropológico el cráneo fue separado del tronco por decapitación, ya sea para causar la muerte, o después de la muerte, y tiene abrasiones dentarias (Campillo, D., 1976-1978). Pertenece a un individuo varón adulto. Al hablar de decapitación hay que hacer mención a tres tumbas de la necrópolis del Turó dels Dos Pins en Cabrera de Mar cuyos restos no presentan huesos del cráneo, cuando normalmente son los más abundantes. Ante ello D. Campillo (1993), se pregunta si son muertos que han sido decapitados antes de la incineración. Otro cráneo con clavo proviene del Puig Castellar de Santa Coloma de Gramanet, hallado al pie de la muralla (Bosch, P., 1915-1920). Junto a él, dos cráneos más con agujero indicando que también estuvieron clavados. A pesar del tiempo transcurrido desde el hallazgo de estos restos tan conocidos y citados en la bibliografía ibérica, no se ha vuel- 
to a identificar ningún cráneo más con estas características. Tan solo en la Penya del Moro de Sant Just Desvern hay un fragmento de parietal que presenta evidencias de haber sido golpeado, y surcos que indican una descarnación, lo que ha sido interpretado por los excavadores como un acto ritual (Belarte, C., Sanmartí, J., 1997). En el sector 11 del Puig de Sant Andreu de Ullastret, se localizó una mandíbula con evidencias de habérsele realizado un corte, lo que podría señalar la existencia de una muerte violenta (Martín, A., 2000).

Diferente es el caso en que encontramos cráneos y otros restos óseos sin ninguna muestra de violencia, al menos visible. En la Illa d'en Reixach en el sector 2, zona 15 se han localizado tres mandíbulas humanas junto a un fragmento de cráneo (Martín, A., et al., 1994). En el Puig de Sant Andreu de Ullastret se han localizado de nuevo restos de al menos cinco individuos (Martín, A., 2000). El sector 11 que es un espacio abierto junto a la muralla y a una puerta del poblado, además de la mandíbula con el corte, habían restos craneales asociados a clavos de hierro. Se trata de tres mandíbulas inferiores y una calota, todo de adultos. En el sector 12, que funcionalmente es una zona de producción a cielo abierto, se localizó la parte superior de un cráneo. En Mas Castellar de Pontós se han exhumado también restos óseos humanos en la casa 1 , departamento 3 , un fragmento de mandíbula. En la casa 2, departamento 1 un fragmento craneal de forma casi rectangular (Agustí, B., 2002). La forma rectangular de este fragmento nos lleva a hacer mención de la necrópolis de Coimbra del Barranco Ancho de Jumilla, en cuya tumba 10 se localizó un fragmento craneal rectangular con signos de trepanación; aunque está claro que podría corresponder al difunto cremado en la tumba, se presenta la posibilidad de que estemos ante un hueso ajeno al difunto, tal vez de un enemigo, que se ha incorporado al ajuar (Porti, M., Martínez, M., 1995). También en la calle 100 de Mas Castellar hay un fragmento mandibular y un cráneo. En la excavación de 1977 se localizó otro fragmento en el sector 1 . Son todo restos de individuos adultos y tan solo uno puede considerarse que tiene trazos masculinos (Agustí, B., 2002). En la Avinguda dels Ferocarrils Catalanas, se halló un cráneo en un nivel de sedimentación aluvial (Vives, E., Miró, C., 1991). En el Tossal del Moro de Pinyeres se cita la existencia de restos humanos. Concretamente dos individuos jóvenes, de ambos sexos, el hombre mayor de 20 años y la mujer sobre los 18 años. Se encontraban por debajo del derrumbe de la pared y en la capa de incendio. Resulta difícil saber si murieron por el incendio que afectó de forma general al asentamiento, por tanto accidentalmente, o eran restos que estaban anteriormente en ese sitio (Arteaga, O., et al., 1990). En el asentamiento de Burriac de Cabrera de Mar se localizó también un maxilar inferior femenino de un individuo adulto (Barberà, J., Pascual, R., 1979-1980). Se conocen restos de cráneo en el Turó de Montgat y en el Molí de l'Espigol de Tornabous, pero no están publicados. Del Puig de la Nau de Benicarló provienen una calota y restos de un cráneo, y otras partes del esqueleto de varios individuos adultos, todo ello en las calles, concretamente en los niveles de derrumbe. Destaca el conjunto de cuatro individuos, tres masculinos y una mujer de la calle $\mathrm{H}$, junto a la muralla, en este caso sin res- 
tos de cráneos. También se hace mención a la presencia de una calota, sin más huesos junto a ella, en el departamento $B$ de un edificio de la Alcudia de Elche, que por el material que se encontró en la excavación, puede corresponder a un lugar de culto (Ramos, R., 1970). En el singular yacimiento de Cancho Roano de Zalamea de la Serena se recuperaron huesos humanos, concretamente según nos informa amablemente el Dr. S. Celestino se trata de un cráneo localizado en el foso, por tanto, de nuevo nos encontramos en lo que podría ser un relleno de un espacio excavado, al igual que los silos.

No queremos pasar por alto, aunque su excavador considera que es un elemento intrusivo dentro de los niveles ibéricos, y que pertenecía a la Edad del Bronce, el resto de cráneo localizado en el depósito votivo del yacimiento albacetense de El Amarejo en la localidad de Bonete (Broncano, S., 1989). Restos de cráneo y mandíbula se han localizado en casas de los yacimientos franceses de le Carla de Bouriège, la Lagaste de Pomas et Rouffiac, l'Agréable de Villasavary, Pech Maho de Sigean, La Liquiere de Calvisson, Vie-Cioutat de Mons, Puech de Lascours de Pailhers. Huesos largos en el yacimiento de La Ramase de Clermont les Ensérune, y en Ensérune de Nissan lez Ensérune, todos ellos en habitaciones. En zonas públicas en Carsac de Carcassonne, en la Lagaste de Pomas et Roufiac, en Pech Maho, cerca de la puerta con una concentración de cráneos, Le Cayla de Mailhac (Dedet, B., Schwaller, M., 1992).

\section{RESTOS HUMANOS PARA LAS HIPÓTESIS}

Como compendio de lo que hemos ido exponiendo en las páginas precedentes, podemos señalar que la cremación aunque el más frecuente, y el que entraría dentro de la práctica funeraria general de al menos los estamentos sociales superiores, es un rito más dentro del mundo funerario ibérico. Tal y como podemos comprobar, cada vez son más las evidencias de los diferentes tratamientos que recibe el cuerpo del muerto, ya sea por pertenecer a un estamento social diferente, por pertenecer al enemigo, por motivo de un rito religioso, por motivo de una decisión «judicial». etc. Por tanto, son restos que pueden provenir de un sacrificio o de una «mala muerte», expresión que B. Dedet (1992), recoge de la etnología africana (Thoma, L., 1982), para designar las muertes acaecidas de una forma que la sociedad no considera la normal, morir lejos de casa, sin descendencia, súbitamente, de forma accidental o violenta, muerte infamante, morir en cinta, o de parto. La mala o la buena muerte condicionarán los funerales y las tumbas, y por lo tanto, el registro arqueológico que llega hasta nosotros y que hemos de interpretar.

Ya hemos comentado la posibilidad de que los enterramientos de recién nacidos sean sacrificios o sustitución de sacrificios, un rito que podemos reseguir desde la Edad del Bronce, tal y como hemos visto más arriba, y continuaría durante la época romana. La variada situación topográfica de los depósitos de huesos infantiles (zonas de almacenaje, murallas, casas), su semejanza con los depósitos 
de animales, el depósito de cadáveres descarnados, la poca cantidad de localizados, cuando habría una fuerte mortalidad infantil, la existencia de enterramientos de neonatos en necrópolis, nos alejan de considerar las inhumaciones infantiles en poblados como simples enterramientos.

Tampoco podemos soslayar la existencia de enterramientos múltiples en las necrópolis. Aunque, hoy por hoy, es imposible conocer su verdadera naturaleza, no deja de llamar la atención la presencia de varios cuerpos en una misma tumba. Cuerpos que según parece, y según se ha comprobado en algunas ocasiones, se han enterrado al mismo tiempo. El acompañamiento de un difunto al más allá, sobre todo en personas de cierta relevancia social, por parte de personas queridas, allegadas o sirvientes no es extraño en diferentes culturas de la Antigüedad. Ello implicaría, pues, el sacrificio de uno de las personas enterradas en la tumba.

Otra de las «malas muerte» la podríamos encontrar en los enterramientos de inhumación en túmulo, las evidencias que aportan el estudio paleopatológico de los restos, así como los paralelos, tal y como hemos indicado, son indicios de la existencia de una muerte violenta, tal vez por lapidación, para la persona enterrada en el Coll del Moro de Tivisa.

En cuanto a los enterramientos en silo el estudio antropológico tampoco nos aporta datos definitivos para su interpretación, pero al igual que sucede con los enterramientos infantiles, podemos establecer ciertos paralelos con los enterramientos de animales. En Mas Castellar de Pontós, en el Turó de la Rovira de Badalona, o en el Bosc del Congost de Sant Julià de Ramís, existen enterramientos de animales en los silos, équidos en los dos últimos, siendo el animal más abundante, hay ovicápridos en el Bosc del Congost, y perro en el mismo yacimiento y en Mas Castellar. El caballo es un animal que se sacrifica entre los pueblos de la península Ibérica según las fuentes escritas. Por tanto, se podría establecer el mismo hecho de que también los enterramientos humanos procedan de sacrificios, al igual que los animales.

La interpretación de los restos humanos aislados en los silos resulta más difícil de realizar. Por una parte, estos silos han sido rellenados con material proveniente de otros lugares, posiblemente de la limpieza de los poblados, por lo que los huesos podrían llegar a los silos como residuo. Siendo pues, los mismos restos que se localizan en los lugares de hábitat. La presencia de la cabeza de un perro en el Mas Castellar de Pontós, animal que es sacrificado ritualmente en el asentamiento, podría indicar también una procedencia como residuo, o también como depósito del sacrificio, por lo que aplicando el paralelismo que hemos comentado en los otros ritos, los restos humanos aislados localizados en los silos serían también un depósito ritual.

En la zona francesa, en Ensérune, localizamos huesos en cisternas, es decir lugares de almacenamiento, en este caso agua, que se han rellenado igual que los silos, y con el relleno se ponen los huesos. El concepto del orificio en la tierra, ya 
sea como cisterna, silo, o foso como el de Cancho Roano, tiene un significado que se nos escapa.

Si no hay lugar a dudas de una muerte violenta es en el caso de los cráneos enclavados del Puig de Sant Andreu de Ullastret y del Puig Castellar de Santa Coloma. Además está la muestra de decapitación de uno de ellos, y la abrasión dentaria como singularización dentro de la sociedad del personaje muerto. Pero junto a estos hallazgos existen otros restos, en su mayoría cráneos y mandíbulas, de los que no se puede deducir la causa de la muerte. Estos restos se encuentran en su mayoría en espacios abiertos, públicos, y en muchas ocasiones junto a las puertas de los asentamientos.

El culto a las cabezas cortadas que se ha querido identificar desde hace tiempo en la península lbérica a través de la iconografía tanto de la escultura como de la decoración cerámicas, siempre se ha relacionado con el mundo celta, teniendo en cuenta además que es un dato que nos ofrecen las fuentes escritas (Blázquez, J.M., 1958; 1962; Balil, A., 1954). En el caso de la Cultura Ibérica, vemos que el registro arqueológico nos indica la presencia de estos restos desde los poblados del mediodía francés hasta el Puig de la Nau de Benicarló, es decir, el nordeste peninsular, una zona que parece a tenor del hallazgo de algunos materiales, como es el caso de las armas, tiene cierta relación con el mundo celta.

La procedencia de estos restos, podría ser el cuerpo de los enemigos, tal y como indican las fuentes escritas, enclavados en la puerta de los poblados o en la puerta del guerrero victorioso que ha producido la muerte. En el ámbito céltico que es el conocido, se indica que las cabezas eran colgadas con clavos como primicias en las casas (Diodoro, V, 29,4; Estrabón, IV, 4,5). En la toma de Selinunte por los Cartagineses en el 409 a.C., se menciona que los mercenarios hispanos ceñían el cuerpo con manos cortadas y otros blandían cabezas en las puntas de lanzas y jabalinas (Diodoro XIII, 57, 2).

Tampoco podemos olvidar la exposición pública como escarnio de los restos de un finado, considerando por otra parte, la presencia de mujeres entre los restos. Este hecho de la exposición pública de los restos del ejecutado ha sido frecuente hasta el siglo XIX, incluso el reparto de las diferentes partes del cuerpo entre varias ciudades para su exposición, como fue el caso del general Rafael Riego. El que se encuentren en algunos casos junto a puertas de las poblaciones y en lugares públicos, apoyaría esta hipótesis de exposición pública.

La presencia de un pilar en el asentamiento de Pech Maho de Sigean, para la exposición de las cabezas, o las conocidas esculturas de Roquepertuse de Velaux, de Entremont, o el monumento de Can Posastres en Sant Martí Sarroca, nos acercan a estas conjeturas de la existencia de ritos religiosos y/o sociales relacionados con las cabezas, ya sea de enemigos de guerra o de ejecutados.

Los restos de cuerpo sin cabeza en una necrópolis, es decir en enterramientos normales, como en el Turó dels Dos Pins, se podría interpretar en la vertiente den- 
tro del culto de las cabezas, de la veneración de los antepasados. Por tanto, se crema y entierra el cuerpo, y se reserva la cabeza para la casa familiar, hallándose en la excavación del poblado.

La existencia tanto de sacrificios humanos, sobre todo en rituales funerarios, como los conocidos de Viriato (Diodoro Sículo, 31, 21; Apiano, Iber, 71), o para seIlar pactos o adivinaciones (Plutarco, QR, 83; Estrabón, III, 3,6), así como de animales, especialmente caballos (Silio Itálico, III, 361; Estrabón, III, 361) entre los pueblos denominados celtas de la Península, nos es conocida por los textos escritos, pero no sucede lo mismo para el área oriental, la zona ocupada por la Cultura Ibérica. No obstante, es evidente la presencia de sacrificios de ovicápridos, caballos o toros ya sea a través del registro arqueológico o de la iconografía. Los paralelos existentes entre los restos de animales sacrificados y los restos humanos nos pueden denunciar el sacrificio de personas en la Cultura Ibérica. El sacrificio no es nada extraño en el contexto de los diferentes pueblos de la Antigüedad, fenicios, púnicos, galos, etruscos, romanos, lusitanos, británicos, un sacrificio que puede ser sustituido por el de un animal, y todo ello antes y después de la Cultura lbérica, por lo tanto, los iberos no serían una excepción, ni en la realización del sacrificio ni en la sustitución de la victima.

Tan solo en las fuentes escritas y dentro del ámbito ibérico podemos encontrar la muerte violenta en el hecho de las luchas funerarias, concretamente en los funerales que Cneo Escipión el Africano ofrece en memoria de su padre y de su tío en Cartagena en el 207 a.C., (Tito Livio, 28, 21). En ellos, dos primos, Corbis y Orma, se ofrecen para dirimir sus disputas de sucesión en una lucha a muerte (Blázquez, J.M., Montero, S., 1993). Este tipo de lucha ritual podría estar representada en las decoraciones cerámicas de Sant Miquel de Llíria (Aranegui, C., 1992). También podría ser el caso de las esculturas de Obulco (Blázquez, J.M., Montero, S., 1993). Por tanto, las muertes violentas se dan incluso entre personas de linajes importantes. Aunque por regla general, en los funerales, se inmolarían tal y como sucede en Roma, prisioneros y siervos jóvenes adquiridos para la ocasión según Tertuliano (De Spect., XII, 2,4).

La tan conocida devotio ibérica llevaría también consigo el sacrificio o al menos la muerte violenta, de la persona que ha jurado la fidelidad. Pocos más son los datos que podemos aportar sobre las muerte violentas según los textos escritos.

En la Península, dentro de un contexto religioso y cultural diferente, ya que es Cádiz, hay sacrificios humanos en honor a Baal Hammon en época de César según se desprende de la lectura de Cicerón (Pro Balbo, 43). Hecho que podrían confirmar los enterramientos infantiles de esta ciudad (Corzo, R., 1989).

Indudablemente la muerte natural o por enfermedad, no es la única dentro del mundo ibérico, y por tanto, el tipo de registro arqueológico localizado tampoco puede ser el mismo para todos. Desde la diferencia social, hasta la diferencia de edad, y el tipo de muerte, marcarán el desarrollo de los funerales y la forma de la 
tumba. Si en Roma que conocemos perfectamente los que habían sufrido una «mala muerte», como los suicidas o los condenados, eran distinguidos por privarles de sepultura, o incluso hasta hace poco tiempo en nuestra cultura los suicidas recibían una sepultura diferenciada, es decir, es un hecho probado a lo largo de la Historia la diferenciación de enterramientos por las formas de muerte, indudablemente los iberos no pueden ser diferentes.

\section{BIBLIOGRAFÍA}

Abad Casal, L., Sala Selles, F. (1991): «Las necrópolis ibéricas del área de Levante», Actas del Congreso de Arqueología Ibérica: Las Necrópolis, pp. 145-167.

AGUSTí FARJAS, B. (1999): «Valoració del material dentari en poblats ibèrics empordanesos», Els productes alimentaris d'origen vegetal a l'edat del Ferro de l'Europa Occidental: de la producció al consum. Sèrie monogràfica, 18, pp. 403-408.

Agustí FARJAS, B. (2002): «Les dades antropològiques». Mas Castellar de Pontós (Alt Empordà). Un complex arqueològic d'època ibèrica (Excavacions 1990-1998), Sèrie Monogràfica, 21, pp. 561-564.

Agustí, B., Burch, J., Carrascal, C., et alii (1998): «Els reompliments de les sitges del Bosc del Congost», Cypsela, 12, pp. 81-95.

ARANEGUI, C. (1992): «Una falcata decorada con inscripción ibérica. Juegos gladiatorios y venationes», SIP Serie de Trabajos Varios, 89. Estudios de Arqueología Ibérica y Romana. Homenaje a Enrique Pla Ballester, pp. 319-344.

Aranegui, C., Jodin, A., Llobregat, E., et alii (1993): La nécropole ibérique de Cabezo Lucero (Guardamar del Segura, Alicante), Madrid. Casa de Velázquez.

Arteaga, O., Padró, J., Sanmartí, E. (1990): El poblado ibérico del Tossal del Moro de Pinyeres (Batea, Terra Alta, Tarragona), Monografies Arqueològiques, 7. Barcelona. Diputación de Barcelona.

BALIL, A. (1954): «Cabezas cortadas y cabezas trofeo en el Levante Español», Congreso Internacional de Ciencias Prehistóricas y Protohistóricas. Actas de la IV sesión, Madrid, pp. 871 y ss.

BARBERÀ, J., PASCUAL, R. (1979-80): «Burriach, un yacimiento protohistórico de la costa Catalana (Cabrera de Mar, Barcelona)», Ampurias, 41-4, pp. 203-242.

BARRIAL Jove, O. (1990): «El ritual del sacrificio en el mundo ibérico catalán», Zephyrus. Revista de Prehistoria y Arqueología, 43, pp. 243-248.

Belarte, M. C., SANMARTí, J. (1997): «Espai de culte i pràctiques rituals a la Catalunya protohistòrica», Quaderns de Prehistòria i Arqueologia de Castelló, 18, pp.7-32.

BLÁzQUeZ MARTíneZ, J. M. (1958): «Sacrificios humanos y representaciones de cabezas en la Península Ibérica», Latomus, 17, pp. 27 y ss.

- (1962): «Cabezas célticas del Castro de Yecla, Salmanca», Actas del VII Congreso Nacional de Arqueología (Barcelona, 1960), Zaragoza, pp. 217-226.

BLÁZQUEZ, J. M., MONTERO, S. (1993): «Ritual funerario y status social: los combates gladiatorios prerromanos en la península ibérica», Veleia, 13, pp. 71-84.

Broncano Rodríguez, S. (1989): El depósito votivo ibérico de El Amarejo (Bonete, Albacete), Excavaciones Arqueológicas en España, 156, Madrid. Ministerio de Cultura.

Bosch Gimpera, P. (1915-1920): «El donatiu de Puig Castellar, per D. Ferran Sagarra, a l'Institut d'Estudis Catalanas», Anuari de l'Institut d'Estudis Catalans, VI, pp. 593-597.

Burch, J., Carrascal, C., Merino, J., Navarro, N. (1995): «L'emmagatzematge en sitges al pla de Girona. L'exemple del Bosc del Congost», Excavacions d'Urgència a Sant Julià de Ramis. Anys 19911993, Monografies 16, pp. 71-84.

Campillo Valero, D. (1976-1978): «Abrasiones dentarias y cráneos enclavados del poblado de Ullastret (Baix Empordà)», Ampurias, 38-40, pp. 317-326.

Campillo Valero, D. (1993): «Estudio de los restos humanos incinerados», en García Rosello, J., Turó dels dos Pins. Necrópolis Ibérica. Mataró-Sabadell, Ausa.

Cela Espin, X., Noguera Guillèn, J., Rovira HortalÀ, M. C. (1999): «Els materials arqueològics del jaciment ibèric del Coll del Moro de Serra d'Almos (Tivissa, Ribera d'Ebre). Col-lecció del Museu Comarcal Salvador Vilaseca de Reus», Pyrenae, 30, pp. 91-121.

Clausell Cantavella, G. (1999): «La incineración 20 de la necrópolis del Torrelló del Boverot (Almazora Castellón)», Quaderns de Prehistòria i Arqueologia de Castelló, 20, pp.115-128. 
CORZo SÁnCHEZ, R. (1989): «Los sacrificios infantiles en Cádiz», Cuadernos de Prehistoria y Arqueología Castellonenses, 14, pp. 239-246.

DEDET, B. (1992): Rites funéraires protohistoriques dans les Garrigues languedociennes. Revue d'Archéologique de Narbonnaise, suplement 24. Carbona, CNRS.

Dedet, B., SCHWALLeR, M. (1990): «Pratique cultuelles et funéraires en milieu domestique sur les oppidums languedociens", Documents d'Archeologie Méridionale, 13, pp.137-161.

FLETCHER VALLS, D. (1947): «Un posible sacrificio fundacional en la ciudad ibérica de Archena». Cuadernos de Historia Primitiva, II, pp. 40-45.

Font SerRA, E. (1980): «Restes humanes de la Cova Freda de Montserrat, atribuides a la cultura ibèrica». Fonaments, 2, pp.71-102.

Garrido, J. P., Garralda, M. D., Muñoz, A., Orta, E. (2000): «Sobre las inhumaciones de la necrópolis orientalizante de la Joya, Huelva: problemática y perspectivas», Actas del IV Congreso Internacional de estudios fenicios y púnicos, IV, Cádiz, pp. 1805-1810.

GUSI JENER, F., (1989) (coord.): «Inhumaciones infantiles en el ámbito mediterráneo español (siglos VII a.E. al II d.E.)", Cuadernos de Prehistoria y Arqueología Castellonenses, 14.

- (1992): «Nuevas perspectivas en el conocimiento de los enterramientos infantiles de época ibérica», SIP Serie de Trabajos Varios, 89, Estudios de Arqueología Ibérica y Romana. Homenaje a Enrique Pla Ballester, pp. 239-260.

LAFUENTE, J. (1929): «La necrópolis ibérica de El Molar», Boletín de la Real Academia de la Historia, $X C I V$, pp. 617-632.

MAIER, J. (1992): «La necrópolis de «La Cruz del Negro» (Carmona, Sevilla): excavaciones de 1900 a 1905», Cuadernos de Prehistoria y Arqueología de la Universidad Autónoma de Madrid, 19, pp. 95119.

Martín Bueno, M. (1975): «Bilbilis. Enterramientos indígenas en torres de muralla», Actas del XII Congreso Nacional de Arqueología (Huelva, 1973), Zaragoza, pp. 701-706.

- (1982): «Nuevos datos para los enterramientos rituales en la muralla de Bilbilis (Calatayud, Zaragoza)", Bajo Aragón. Prehistoria, IV, pp. 96-105.

Martín Ortega, A. (2000): «L'Oppidum del Puig de Sant Andreu d'Ullastret. Aportació de les intervencións arqueològiques recents al coneixement dels sistemes defensius i de l'urbanisme", L'Hàbitat protohistòric a Catalunya, Roselló i Llenguadoc Occidental. Actualitat de l'arqueología de l'edat del Ferro. Serie Monográfica, 19, pp.107-122.

Martín, M. A., López, J. B., LloRens, J. M., et alii (1994): «El jaciment de l'llla d'en Reixac d'Ullastret. Campanyes de 1992 i 1993", Actes de les 2 Jornades d'Arqueologia de les comarques de Girona. Torroella de Montgri, pp. 38-45.

Noguera Guillén, J. (2002): Ibers a l'Ebre, Flix, Centre d'Estudis de la Ribera d'Ebre.

NoRDSTROM, S. (1973): La ceramique peinte iberique de la province d'Alicante. Parte I. Acta Universitatis Stockholmiensis Stockholm Studies in Classical Archaeology. Estocolmo, Gosya Saflund.

OLIVER FoIx, A. (1995): «Acerca de los restos humanos localizados en los poblados ibéricos», Arx, 1, pp. 35-41.

- (2005): «La necrópolis ibérica del Mas Nou de Bernabé en Tirig-Salzadella (Castellón)», Saguntum 37, pp. 45-58.

Pérez Almoguera, A. (1998): «Tres casos de rituales fundacionales o propiciatorios en construcciones domésticas en el alto imperio romano. ¿Latinidad o indigenismo?», Arys. Antigüedad: Religiones y Sociedades, 1, pp. 195-206.

Portí Durán, M., Martínez Andreu, M. (1995): «Un fragmento craneal trepanado procedente de la necrópolis ibérica de Coimbra del Barranco Ancho (Jumilla)», Verdolay, 7, pp. 287-291.

PujoL, J., GarCíA, J. (1982-1983): «El grupo de sitges de Can Miralles-Can Modolell (Cabrera de Mar-el Maresme). Un jaciment d'epoca ibèrica situat en la rodalia del poblat de Burriac». Laietania. Estudis d'Historia i d'Arqueologia de Mataró i del Maresme, 2-3, pp. 46-145.

RAmos Folqués, A. (1970): Excavaciones en La Alcudia (Elche). SIP Serie de Trabajos Varios, 39. Valencia, Diputación de Valencia.

Reverte ComA, J. M. (1985): «La necrópolis ibérica de Pozo Moro (Albacete). Estudio anatómico, antropológico y paleopatológico», Trabajos de Prehistoria, 42, pp. 195-282.

- (1990): «Estudio antropológico y paleopatológico de los restos óseos cremados de Los Villares (Hoya Gonzalo) 1983-1984", en BLÁNQUEZ PÉREZ, J. J., La formación del mundo ibérico en el sureste de la Meseta (Estudio arqueológico de las necrópolis ibéricas de la provincia de Albacete), pp. 521613. Albacete, Instituto de Estudios Albacetenses.

Ribas Beltrán, M., MARTín Tobias, R. (1960-1961): «Hallazgo de silos ibéricos en Burriac (Cabrera de Mataró)», Ampurias, 22-23, pp. 298-306. 
Ruiz Rodríguez, A., Molinos Molinos, M. (2005): «En la vida y en la muerte: el final del periodo orientalizante en el Alto Guadalquivir», Actas del III Simposio Internacional de Arqueología de Mérida: Protohistoria del Mediterráneo Occidental. El Periodo Orientalizante, vol. II. Anejo de Archivo Español de Arqueología, XXXV, pp. 787-798.

Santonja Alonso, M. (1992): «Problemática de los enterramientos infantiles en las necrópolis de El Cigarralejo, Pozo Moro y los Villares», Boletín de la Asociación Española de Amigos de la Arqueología, 32, pp. 37-38.

- (1993): «Necrópolis ibérica de «El Cigarralejo». Estudio osteológico (comparado con los ajuares)», Espacio, tiempo y forma., S. II, 6, pp. 297-348.

SenENT, J. J. (1930): «Excavaciones en la necrópolis de El Molar». Memorias de la Junta Superior de Excavaciones Arqueológicas, 107. Madrid.

TARACENA, B. (1943): «Cabezas-trofeo en la España céltica», Archivo Español de Arqueología, XVI, pp$151-171$.

Thoma, L. V. (1982): La mort africaine. Ideologie funéraire en Afrique Noire. París, Payot.

Vilaseca Anguera, S. (1953): Coll del Moro. Yacimiento posthallstáttico. Estudios lbéricos, 1. Valencia, Diputación de Valencia.

VIVES, E., MıRó, C. (1991): «Restos humanos de época ibérica en Montjuic (Barcelona). La excavación de la Avinguda dels Ferrocarrils catalans —antiga via de Magoria— en la montaña de Montjuic», Nuevas perspectivas en Antropología, Vol. II, pp. 1073-1088. 


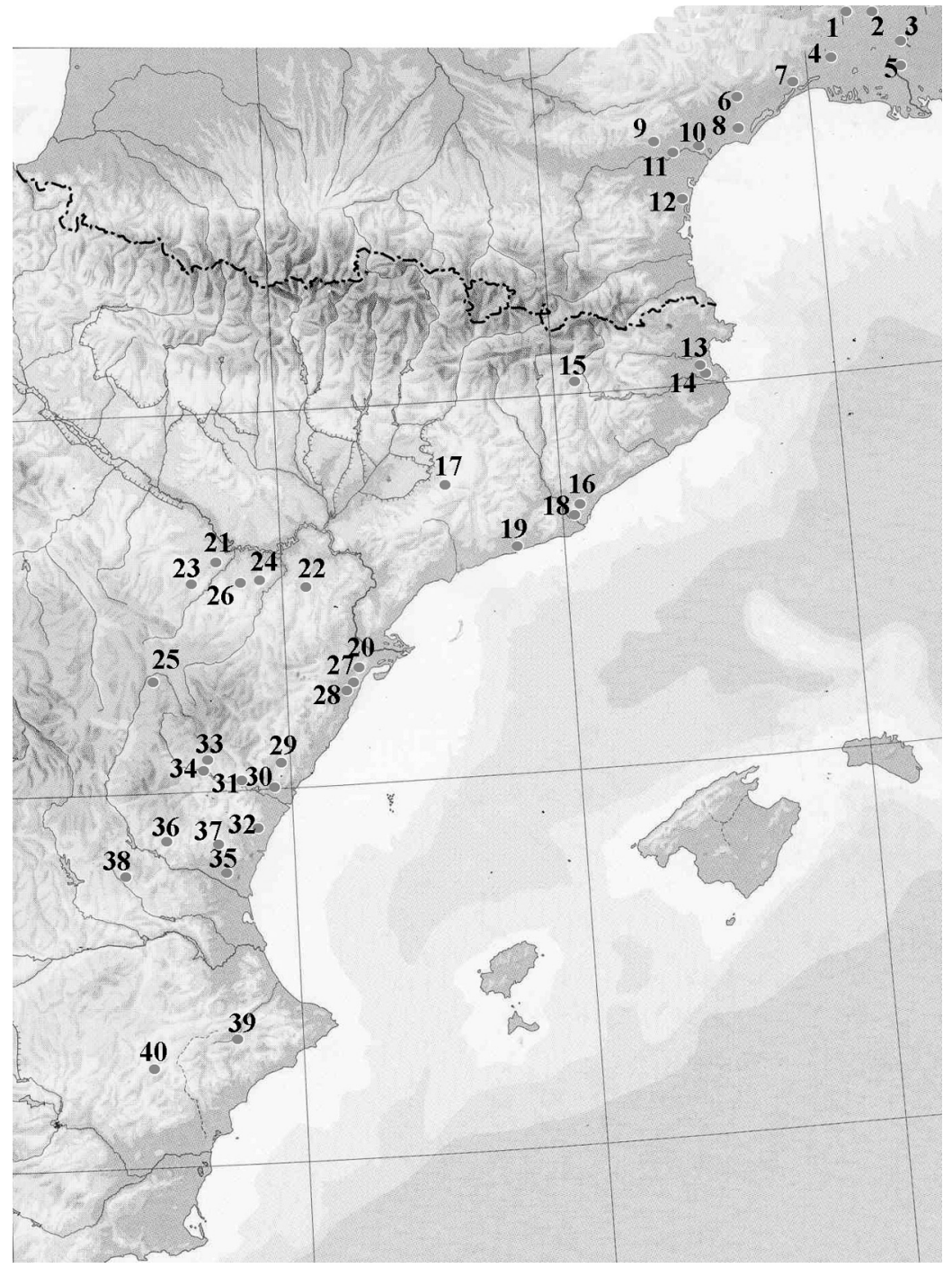

Fig. 1. Inhumaciones infantiles en lugares de hábitat. Basado especialmente en F. Gusi, y B. Dedet-M. Sschwaller: 1.- L'Ermitage, Alès. 2.- Vié-Cioutat, Mons. 3.- Le Marduel, Saint Bonnet du Gard. 4.- Plan de la Tour, Gailhan. 5.- Mas Saint Jean, Bellegarde. 6.- La Ramasse, Clermont l'Hérault. 7.- Lattes. 8.- La Monédière, Bessan. 9.- Cayla, Mailhac. 10.- Ensérune, Nissan lez Ensérune. 11.- Montlaurès, Narbonne. 12.- Pech Maho, Sigean. 13.- Puig de Sant Andreu, Ullastret. 14.- Illa d'en Reixach, Ullastret. 15.Camp Maurí, La Valldan-Berga. 16.- Turó de Ca n'Olivé, Cerdanyola del Vallés. 17.- Molí de l'Espigol, Tornabous. 18. - Penya del Moro, Sant Just Desvern. 19.- Darró, Vilanova i la Geltrú. 20.- Moleta del Remei, Alcanar. 21.- Castillejo de la Romana, Puebla de Hijar. 22.- Piuró del Barranc Fondo, Mazaleón. 23.El Palomar, Oliete. 24.- El Tarratrato, Alcañiz. 25.- Alto Chacón, Teruel. 26.- San Antonio, Calaceite. 27.Puig de la Misericordia, Vinaròs. 28.- Puig de la Nau, Benicarló. 29.- Els Estrets, Vilafamés. 30.- Les Forques, Borriol. 31.- Montmirà, l'Alcora. 32.- Sant Josep, la Vall d'Uixó. 33.- La Escudilla, Zucaina. 34.- Los Cabañiles, Zucaina. 35. - Castellet de Bernabé, Lliria. 36.- La Seña, Villar del Arzobispo. 37.- Puntal dels Llops, Olocau. 38.- Los Villares, Caudete de las Fuentes. 39.- La Serreta, Alcoy. 40.- La Alcudia, Elche. 41.- Coimbra del Barranco Ancho, Jumilla. 


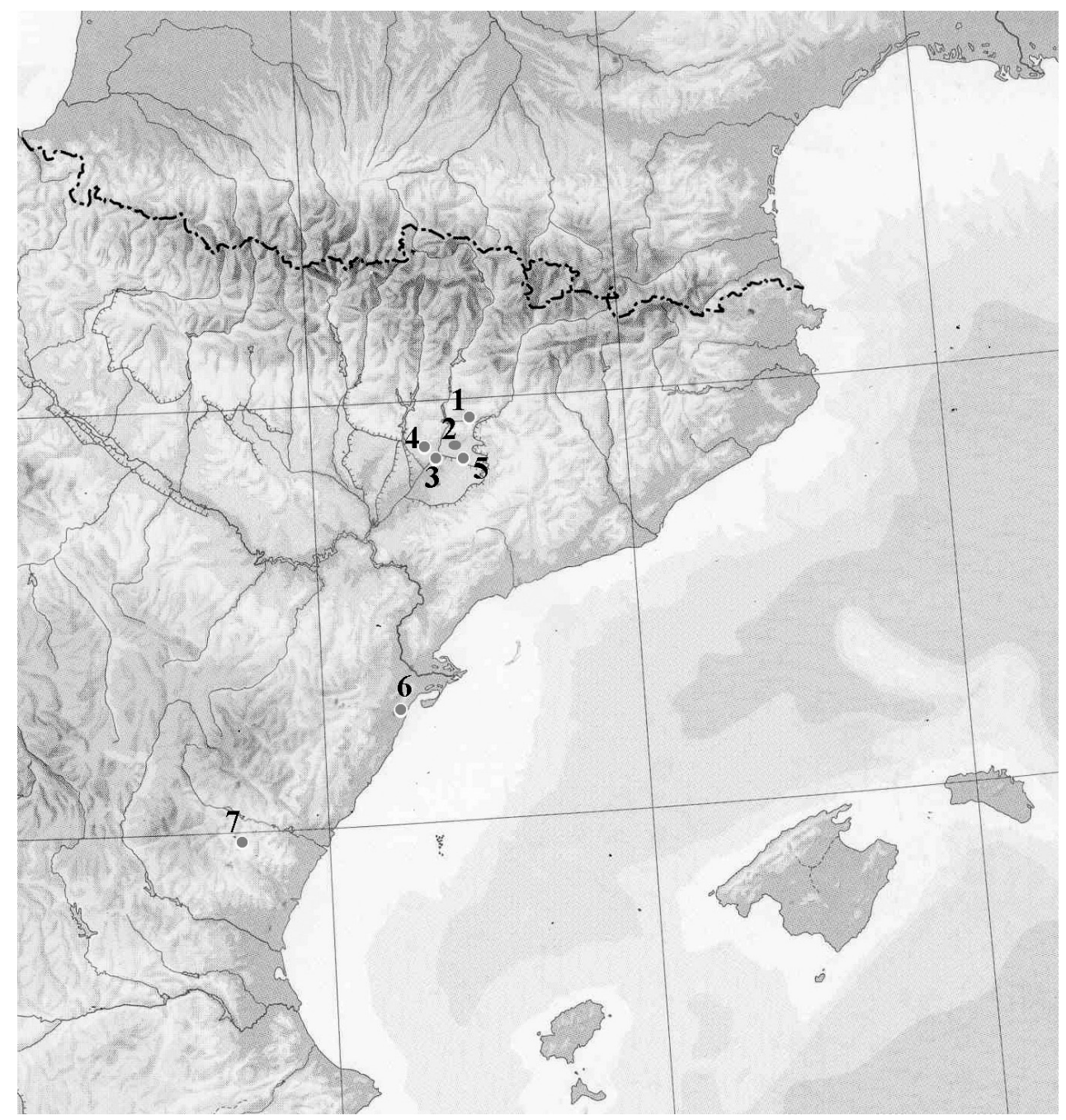

Fig. 2. Inhumaciones infantiles del Bronce final: 1.- La Pedrera, Vallfogona. 2.- Tossal de les Tenalles de Sidamont. 3.- Carretela, Aitana. 4.- Azafranales, Fraga. 5.- Els Vilars, Arbeca. 6.- Moleta del Remei, Alcanar 7.- Peña de las Dueñas, Teresa. 


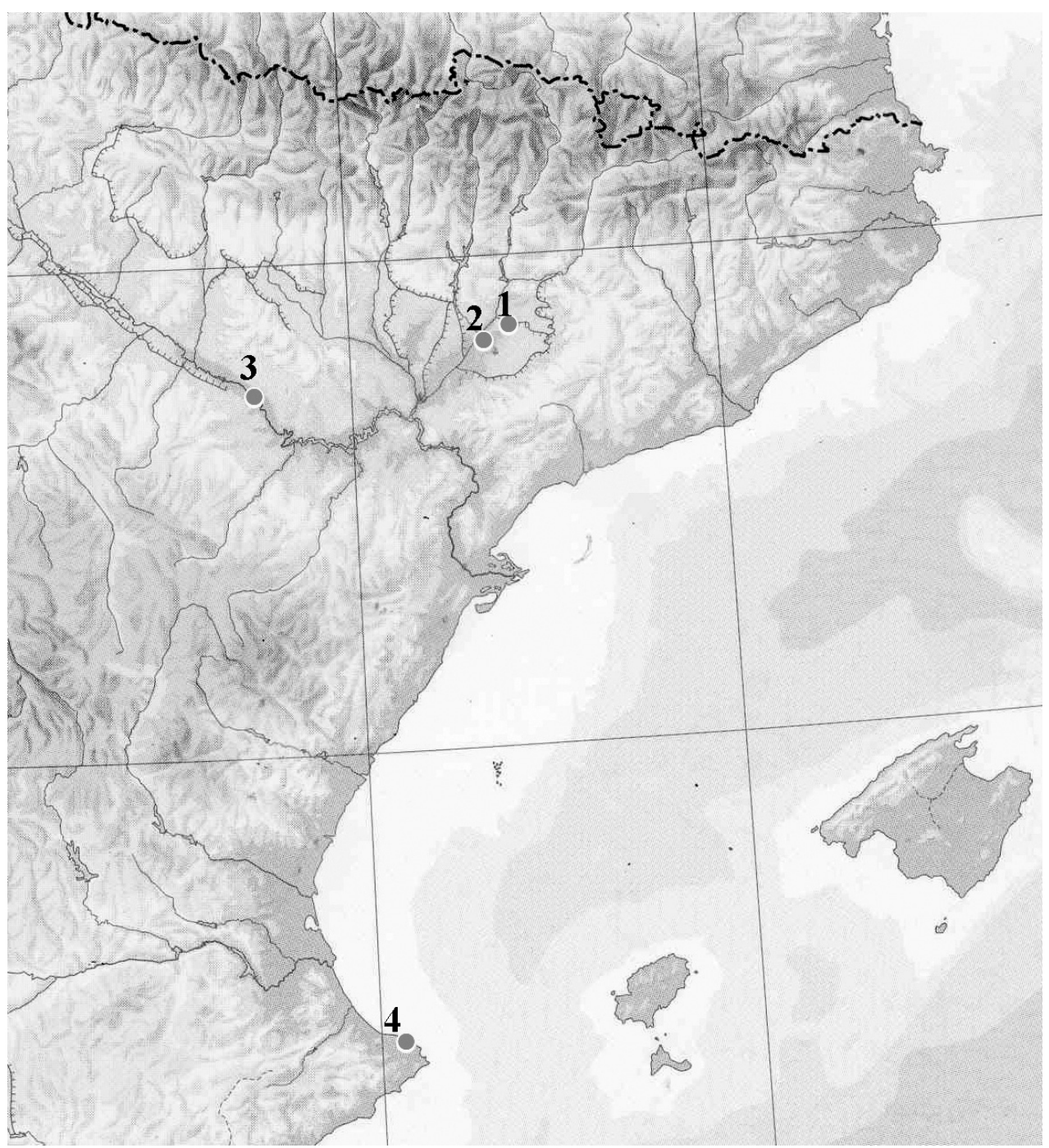

Fig. 3. Inhumaciones infantiles en lugares de hábitat de época romana: 1.- Tossal del Moro, Corbins. 2.- Portal Antic de la Magdalena, Lérida. 3.- Celsa, Velilla de Ebro. 4.- Denia. 


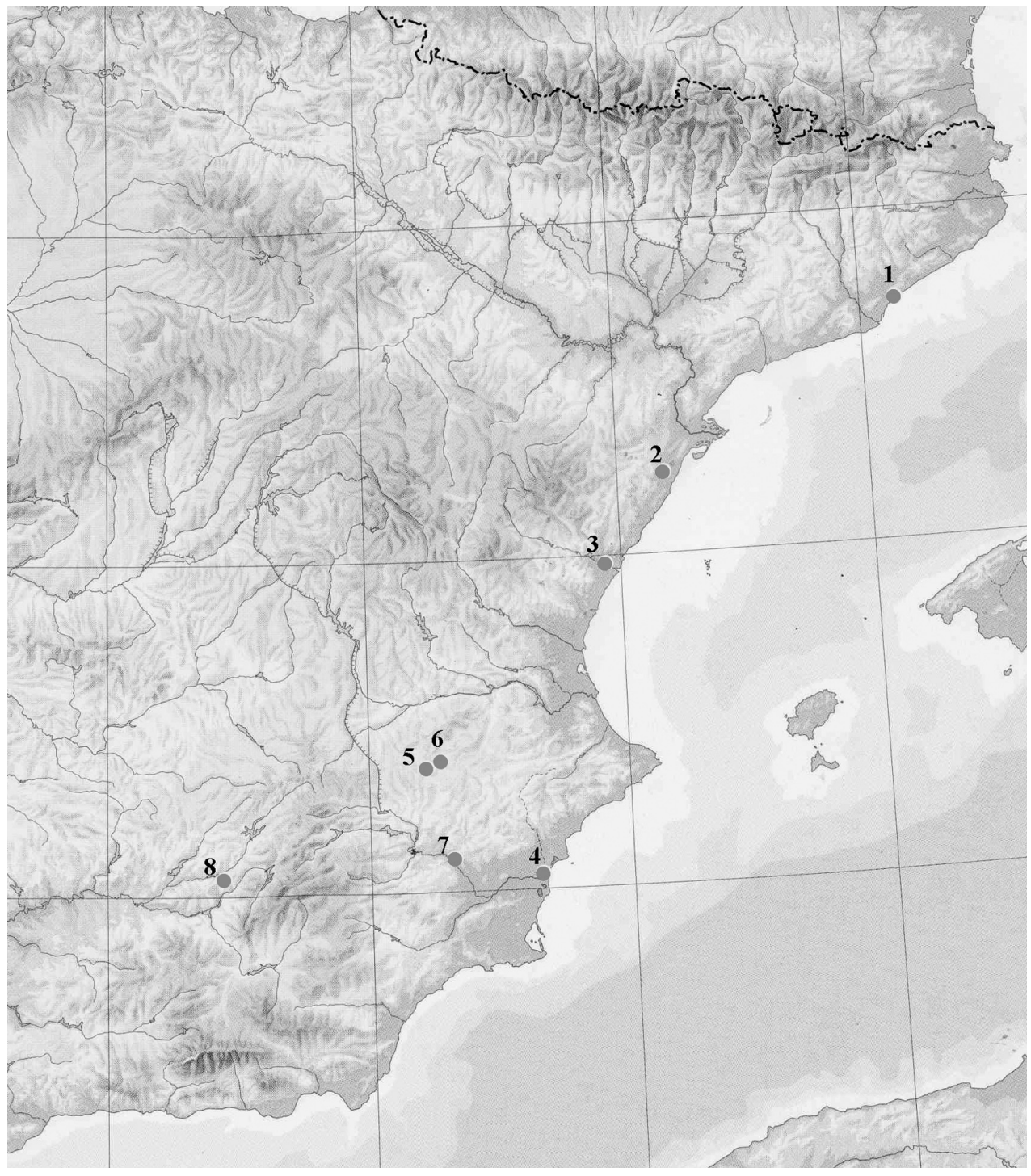

Fig. 4. Enterramientos múltiples en necrópolis: 1.- Turó dels Dos Pins, Cabrera de Mar. 2.- Mas Nou de Bernabé, Tirig -Salzadella. 3.- El Boverot, Almazora. 4.- Cabezo Lucero, Guardamar del Segura. 5.- Pozo Moro, Chinchilla. 6.- Los Villares, Hoya Gonzalo.7.- El Cigarralejo, Mula. 8.- Hornos de Peal, Peal de Becerro. 


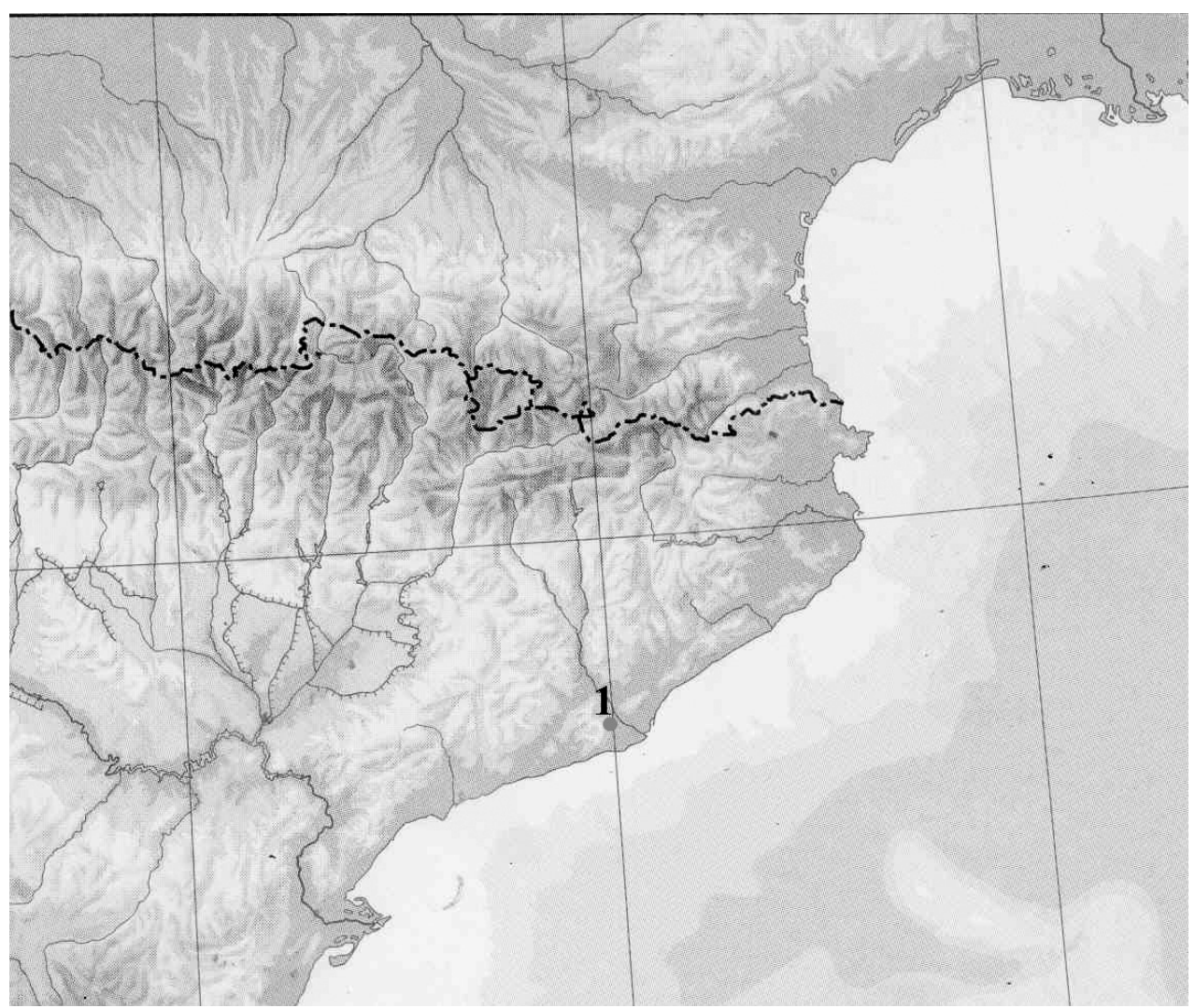

Fig. 5. Enterramiento en cueva: Cova Freda de Collbató. 


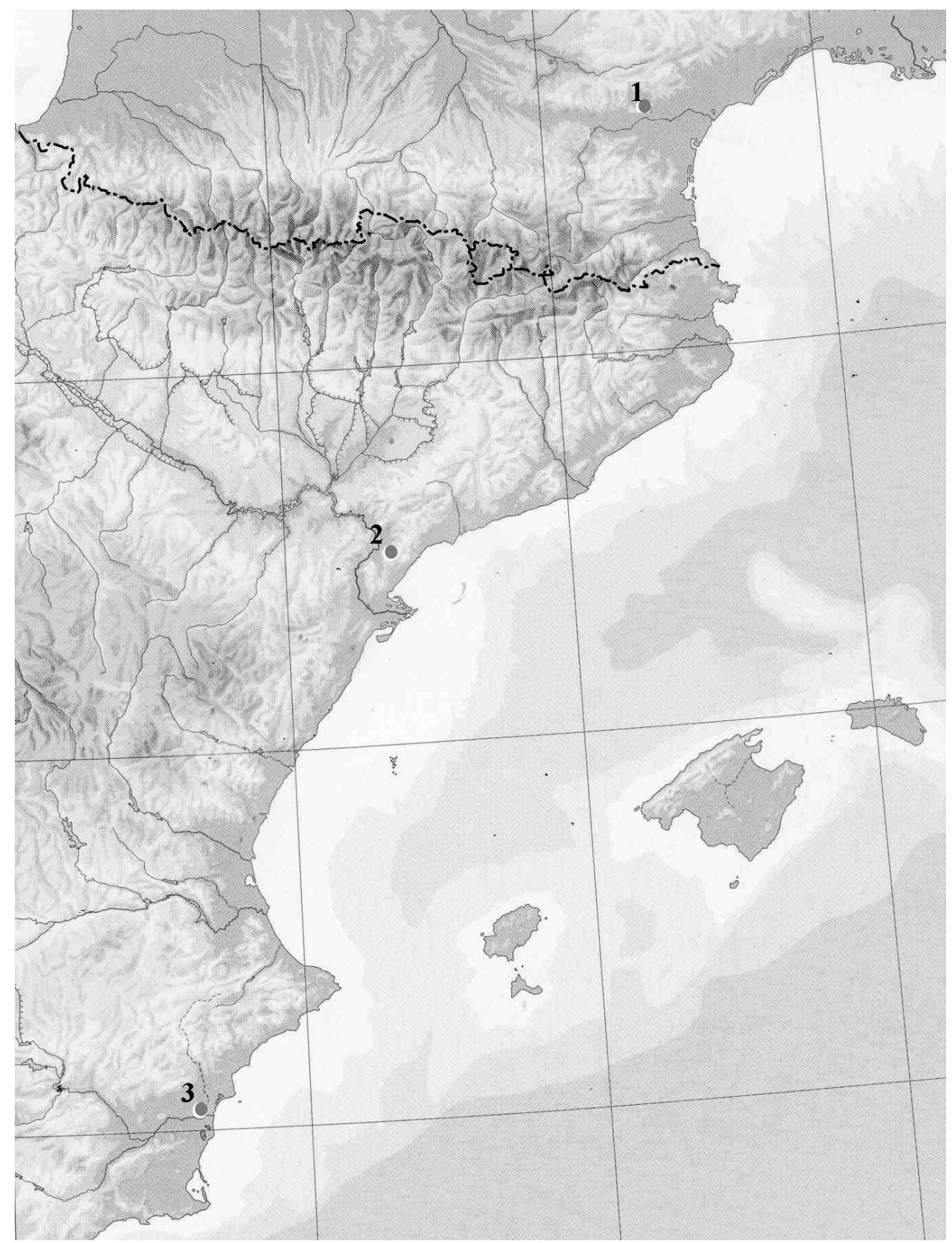

Fig. 6. Enterramientos bajo «túmulo»: 1.- Cayla, Mahilac. 2.- Coll del Moro, Tivisa. 3.- El Molar, San Fulgencio. 


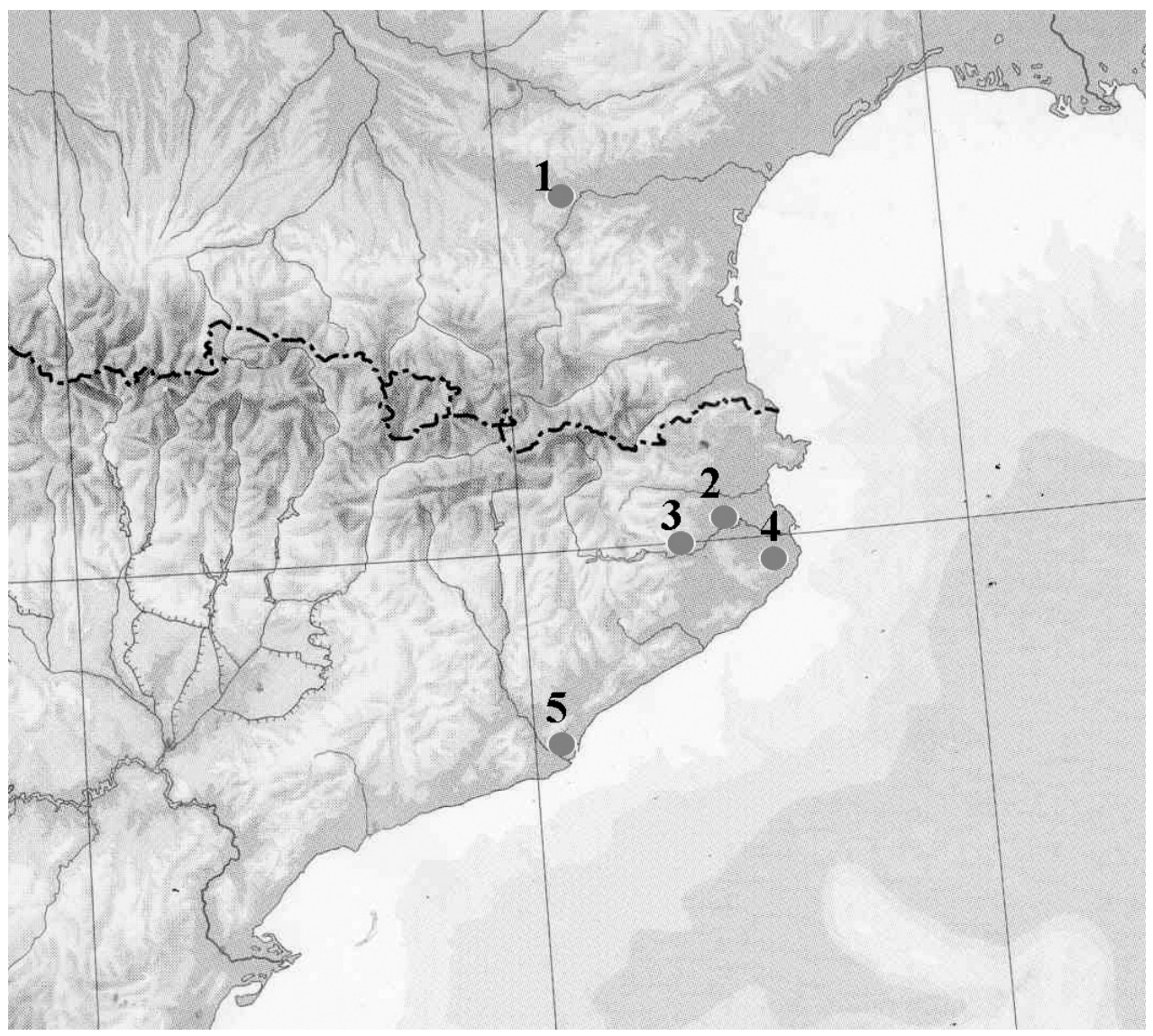

Fig. 7. Enterramientos en silos: 1.- Lagaste, Pomas et Rouffiac. 2.- Quintana, Cervià de Ter. 3.- Bosc del Congost, Sant Julià de Ramis. 4.- Sant Sebastià de la Guarda, Palafrugell. 5.- Montjuic, Barcelona. 


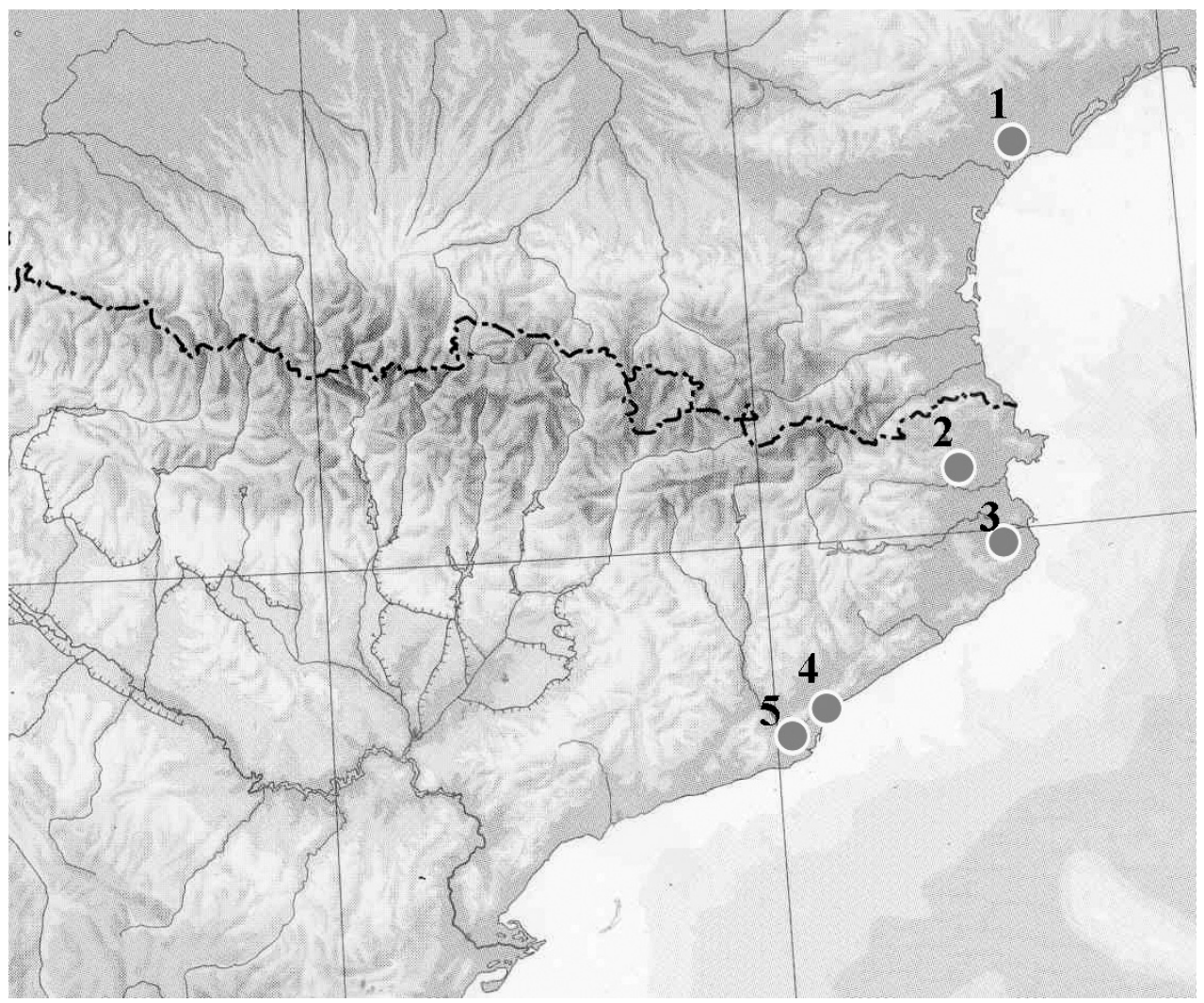

Fig. 8. Huesos humanos en silos: 1.-Ensérune, Nissan lez Ensérune. 2.- Mas Castellar, Pontós. 3.- Puig de Sant Andreu, Ullastret. 4.- Burriac, Cabrera de Mar. 5.- Montjuic, Barcelona. 


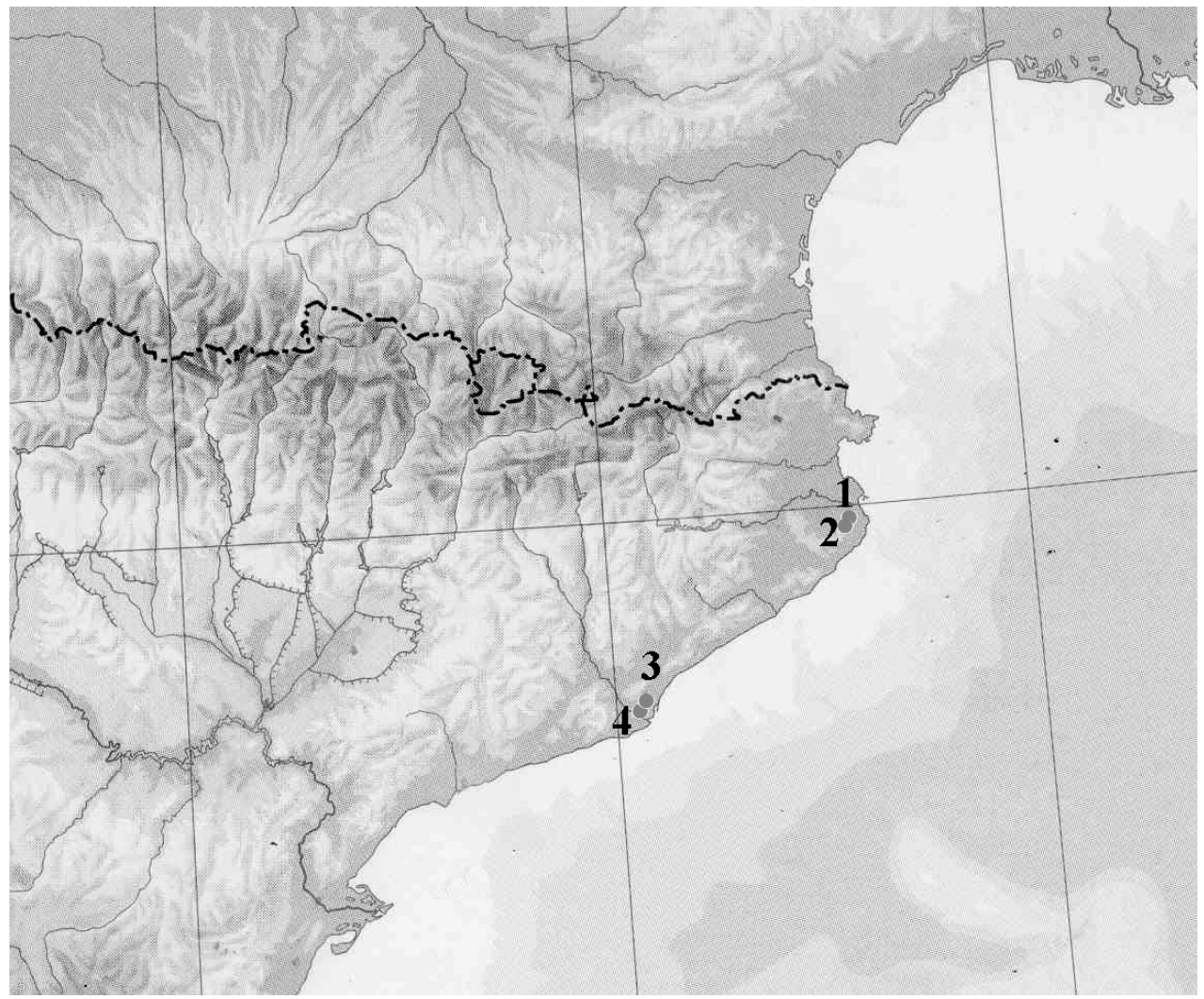

Fig. 9. Evidencias de muerte violenta en lugares de hábitat: 1.- Illa d'en Reixach, Ullastret. 2.- Puig de Sant Andreu, Ullastret. 3.- Puig Castellar, Santa Coloma de Gramanet. 4.- Penya del Moro, Sant Just Desvern. 


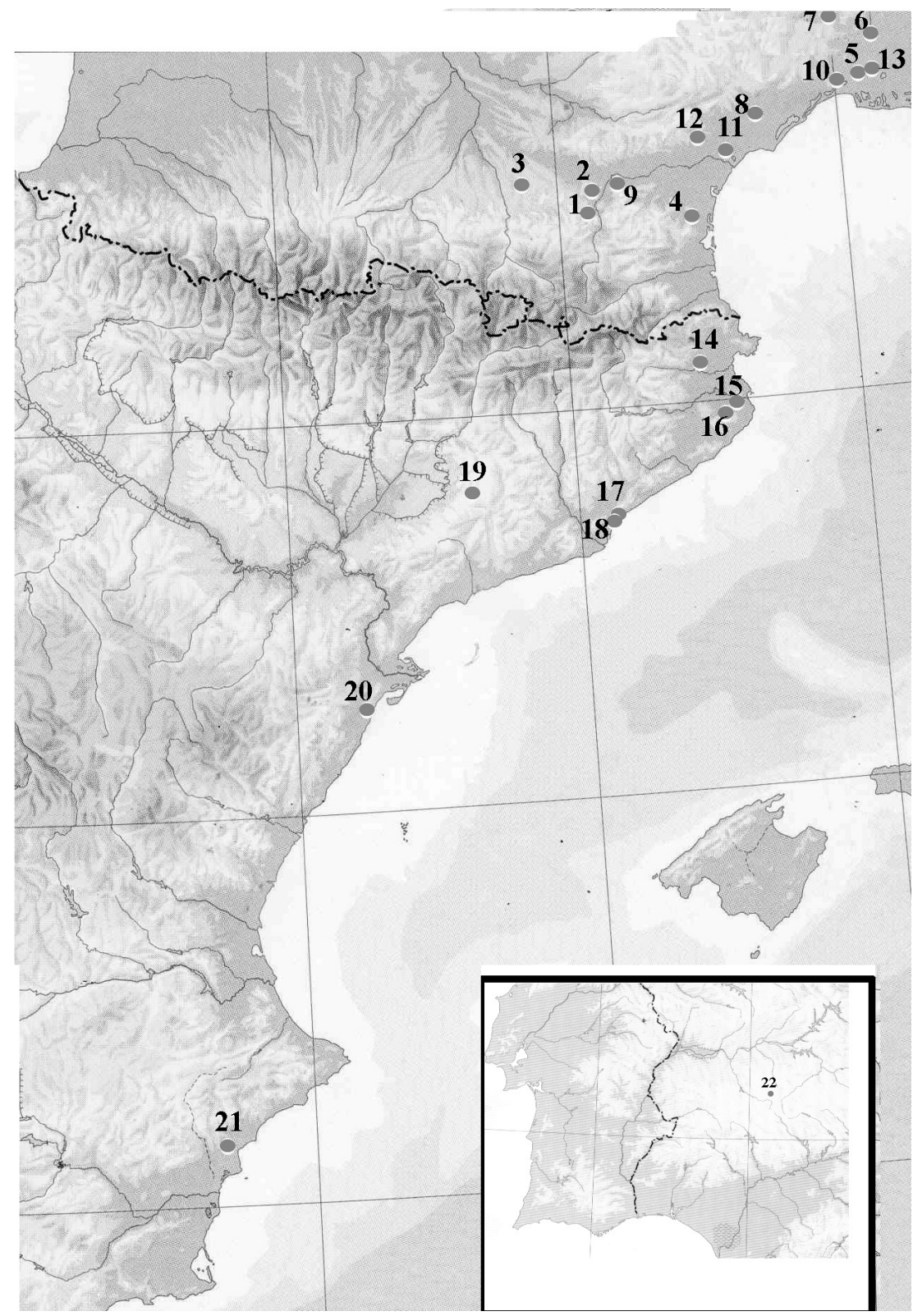

Fig. 10. Yacimientos con huesos humanos en lugares de hábitat: 1.- Carla, Bouriège. 2.- Lagaste, Pomas et Rouffiac. 3.- Agréable, Villasavary. 4.- Pech Maho, Sigean. 5.- La Liquiere, Calvisson. 6.- Vie-Cioutat, Mons. 7.- Puech, Lascours de Pailhers. 8.- La Ramase, Clermont les Ensérume. 9.- Carsac, Carcassonne. 10.- Ambrussum, Villetelle. 11.- Ensérune, Nissan Lez Ensérune. 12.- Le Cayla, Mailhac. 13.- Roque-de-Viou,Saint Dionisy (Bronce final). 14.- Mas Castellar, Pontós. 15.- Illa d'en Reixach, Ullastret. 16.Puig de Sant Andreu, Ullastret. 17.- Burriac, Cabrera de Mar. 18.- El Turó, Montgat. 19.- Molí de l'Espigol, Tornabous. 20.- Puig de la Nau, Benicarló. 21.- La Alcudia, Elche. 22.- Cancho Roano, Zalamea de la Serena. 